\title{
Dynamic Identification and Early Warning of Investment Inefficiency of Listed Companies in China--Based on the Perspective of Model Building and Upgrading
}

\author{
Hong-Tao LIU* \\ Shaoyang University, Shaoyang, 422000, China \\ rrsh248@163.com \\ ${ }^{*}$ Corresponding author
}

\begin{abstract}
Keywords: Investment inefficiency, Identification; Early warning, The two-tier stochastic frontier model, China.
\end{abstract}

\begin{abstract}
Investment is the driving force of economic growth, but inefficient investment behavior can be seen everywhere. How to identify the inefficient investment, and grasp the early warning technology for inefficient investment behavior is very practical significance. Based on the construction and upgrading of the two-tier stochastic frontier model to overcome the shortcomings of previous practices, we have carried on the thorough analysis to the Current topic, and has drawn the conclusion: (1) The result of model comparison before and after upgrade is that:Compared to the annual growth rate, using of Tobin's $Q$ to measure the investment opportunities of the enterprise is more valuable. (2) The result of identifying inefficient investment behavior is that: From a macro perspective, the overall performance of Listed Companies in China is lack of investment; but on the micro level, the investment offset caused by investment game is not balanced in different years. (3) The result of early-warning inefficient investment behavior is that:When exogenous variables are introduced into the upgraded model, the newly synthesized model is able to recognize the interference intensity of game factors; At the present stage of China, the improvement of the corporate debt ratio is not a magic weapon to restrict the management's wanton investment.
\end{abstract}

\section{Introduction}

Investment is the driving force of economic growth, its efficiency is directly related to the fate of the enterprise and the country's safety. However, in reality, due to many factors, not all investment behavior is effective. How to overcome the inefficient investment has become the most widespread interest in academia and practice circle.

How to identify the inefficient investment, the most recognized is Structural investment expectation model proposed by Richardson. In this model, the actual investment expenditure is divided into two parts: expected and unexpected investment, the former is used to indicate the appropriate investment level determined by the factors such as company size and growth, the latter is used to describe the deviation of the actual investment expenditure to the appropriate investment expenditure. If unexpected investment is greater than zero, it indicates that the company has excessive investment, on the contrary, it means that the enterprise is lack of investment.

However, the investment expectation model can be used to determine whether a company has inefficient investment, but it is not easy to analyze the causes of inefficient investment. The first goal of this paper is to find a convenient way to identify inefficient investment behavior and to establish an effective early warning mechanism to intervene inefficient investment behavior. The difference between the previous approach and the previous one is that Richardson (2006) investment expectation model is not used as a tool for identifying inefficient investment behavior, but as a weapon to estimate the optimal investment frontier; Besides, According to the traditional $Q$ theory, under the assumption of perfect capital market, the firm's investment expenditure has an optimal boundary determined by investment opportunities [1], Compared with the traditional use of revenue growth rate to build the optimal investment boundary, the use of investment opportunities to build the optimal investment boundary has a higher credibility; In conclusion, Instead of 
constructing Richardson (2006) investment expectation model, the two-tier stochastic frontier model can not only achieve the first goal of this paper, but also created the opportunity to upgrade and compare the model, which constitutes the second goal of this paper.

The structure of this paper is organized as follows: In the first part, we introduce the construction and upgrading process of two-tier stochastic frontier model; The second part is Data selection and Empirical results; The third part is the conclusion.

\section{The Construction and Upgrading of Two-tier Stochastic Frontier Model}

According to the traditional $Q$ theory, under the assumption of perfect capital market, there exists an optimal boundary of investment expenditure(Hayashi,1982):

$$
I_{i t}=I_{i t}^{*}+\varepsilon_{i t}
$$

Considering the characteristics of the two-tier stochastic frontier model, we can rewrite the (1) as (2) :

$$
I_{i t}=I_{i t}^{*}+\varepsilon_{i t} ; \quad \varepsilon_{i t}=v_{i t}-u_{i t}+w_{i t}
$$

Among them, $I_{i t}$ is the actual investment expenditure of enterprise $\mathrm{i}, I_{i t^{*}}$ is the optimal investment boundary. $v_{i t}$ is a general random interference term, $u_{i t} \geq 0$ used to measure the extent of the actual level of investment that is lower than the optimal investment boundary due to the presence of the curbing factor, $w_{i t} \geq 0$ is used to measure the extent of the actual level of investment that is higher than the optimal investment boundary due to the presence of the inducing factors.

How to obtain the optimal investment boundary is a difficult problem in the academic circles, The common method is to use Richardson (2006) investment expenditure expectation model to simulate the optimal investment boundary,So we construct formula (3):

$$
\begin{aligned}
& I_{i t}=\beta_{0}+\beta_{1} \text { Growth }_{i t-1}+\beta_{2} \text { Lev }_{i t-1}+\beta_{3} \text { Cash }_{i t-1}+\beta_{4} \text { Age }_{i t-1}+\beta_{5} \text { Size }_{i t-1}+\beta_{6} \text { Return }_{i t-1} \\
& +\beta_{7} I_{i t-1}+\sum \text { Industry }+\sum \text { Year }+\varepsilon_{i t} ; \quad \varepsilon_{i t}=v_{i t}+w_{i t}-u_{i t}
\end{aligned}
$$

Among them, Growth it-1 $_{1}$ is the Revenue Growth Rate, Lev $v_{i t-1}$ is the Debt Ratio, Cash $_{t-1}$ is the Cash Stock, Age $_{i t-1}$ is Time to Market, Size $e_{i t-1}$ is the Size of the company, Return it-1 $_{1}$ is Stock Returns , $\sum$ Industry is the industry dummy variables, $\sum$ Year is the year dummy variable.

But as mentioned above, We think: (1) According to the traditional $Q$ theory, under the assumption of perfect capital market, the firm's investment expenditure has an optimal boundary determined by investment opportunities (Hayashi, 1982); (2) Taking into account the fact that China's capital market is not perfect [2], Tobin's $Q$ value can not be directly used to replace investment opportunities. Therefore, we can consider the use of Tobin's $Q$ variables to construct upgrade model of (3), so get (4):

$$
\begin{aligned}
& I_{i t}=\beta_{0}+\beta_{1} \text { TobinQ }_{i t-1}+\beta_{2} \text { Lev }_{i t-1}+\beta_{3} \text { Cash }_{i t-1}+\beta_{4} \text { Age }_{i t-1}+\beta_{5} \text { Size }_{i t-l}+\beta_{6} \text { Return }_{i t-1} \\
& +\beta_{7} I_{i t-1}+\sum \text { Industry }+\sum \text { Year }+\varepsilon_{i t} ; \quad \varepsilon_{i t}=v_{i t}+w_{i t}-u_{i t}
\end{aligned}
$$

The model is estimated using the maximum likelihood method, the statistical tool used is STATA 14.0 .

\section{Data Selection and Empirical Results}

\section{Data Selection}

In this paper, the Shanghai and Shenzhen Stock Exchange from January 1, 2007 to December 31, 2013, A shares of listed companies as the research object. All the data are taken from the CSMAR(China Stock Market \& Accounting Research Database). The sample is selected as follows: (1) In view of the special nature of the financial sector, to avoid such listed companies; (2) Because the financial status of ST company is abnormal, it should be eliminated; (3) Finally, 5,665 samples 
of 1133 companies in the period from 2009 to 2013 were obtained.

Table 1 Descriptive statistics of variables

\begin{tabular}{ccccc}
\hline Variable & Mean value & Standard deviation & Minimum & Maximum \\
\hline Iit & -3.367 & 1.426 & -11.970 & 1.739 \\
Iit-1 & -3.287 & 1.424 & -14.019 & 1.739 \\
Growthit-1 & 0.576 & 20.124 & -0.984 & 1497.160 \\
TobinQit-1 & 2.180 & 1.474 & 0.602 & 22.739 \\
Levit-1 & 0.516 & 0.204 & 0.007 & 2.033 \\
Cashit-1 & 0.206 & 0.293 & 0.001 & 10.596 \\
Ageit-1 & 12.620 & 4.369 & 5 & 22 \\
Sizeit-1 & 22.016 & 1.299 & 18.147 & 28.405 \\
Returnit-1 & 0.151 & 0.836 & -0.869 & 6.909 \\
\hline
\end{tabular}

\section{Empirical Results}

Model Comparison Before And After Upgrade. Based on the discussion of the first part of this paper, we compare the pros and cons of the model before and after the upgrade. The results are shown in Table 2.

Table 2 Two-tier stochastic frontier estimation

\begin{tabular}{|c|c|c|c|c|c|}
\hline \multicolumn{3}{|c|}{ Model I } & \multicolumn{3}{|c|}{ Model II } \\
\hline Variable & coefficient & $\mathrm{p}$ - value & Variable & coefficient & $\mathrm{p}$ - value \\
\hline Investment: $\mathrm{I}_{\mathrm{it}}$ & \multicolumn{5}{|c|}{ Investment: $\mathrm{I}_{\mathrm{it}}$} \\
\hline $\mathrm{I}_{\mathrm{it}-1}$ & $0.796 * * *$ & 0.000 & $\mathrm{I}_{\mathrm{it}-1}$ & $0.793 * * *$ & 0.000 \\
\hline Growth $_{\text {it- } 1}$ & $-0.001 * * *$ & 0.000 & Tobin $_{\text {it- } 1}$ & $0.050 * * *$ & 0.000 \\
\hline $\operatorname{Lev}_{\text {it }-1}$ & $-0.359 * * *$ & 0.000 & $\operatorname{Lev}_{\text {it-1 }}$ & $-0.288 * * *$ & 0.000 \\
\hline Cash $_{\text {it-1 }}$ & $-0.211 * * *$ & 0.000 & Cash $_{\text {it-1 }}$ & $-0.245^{* * *}$ & 0.000 \\
\hline $\mathrm{Age}_{\mathrm{it}-1}$ & $-0.005^{* *}$ & 0.041 & $\mathrm{Age}_{\mathrm{it}-1}$ & $-0.004 *$ & 0.067 \\
\hline Size $_{\mathrm{it}-1}$ & -0.010 & 0.229 & Size $_{\mathrm{it}-1}$ & 0.005 & 0.560 \\
\hline Return $_{\text {it-1 }}$ & $0.123 * * *$ & 0.000 & Return $_{\text {it-1 }}$ & $0.093 * * *$ & 0.000 \\
\hline Cons & -0.207 & 0.265 & Cons & $-0.690 * * *$ & 0.001 \\
\hline $\begin{array}{r}\text { Random: } \sigma_{\mathrm{v}} \\
\text { Cons }\end{array}$ & \multicolumn{5}{|c|}{ Random: $\sigma_{\mathrm{v}}$} \\
\hline Underinvestment: $\sigma_{\mathrm{u}}$ & \multicolumn{5}{|c|}{ Underinvestment: $\sigma_{\mathrm{u}}$} \\
\hline Cons & $-0.467 * * *$ & 0.000 & Cons & $-0.465 * * *$ & 0.000 \\
\hline Overinvestment: $\sigma_{\mathrm{w}}$ & \multicolumn{5}{|c|}{ Overinvestment: $\sigma_{\mathrm{w}}$} \\
\hline Cons & $-0.545^{* * *}$ & 0.000 & Cons & $-0.548 * * *$ & 0.000 \\
\hline $\mathrm{N}$ & \multicolumn{2}{|c|}{5,665} & $\mathrm{~N}$ & \multicolumn{2}{|c|}{5,665} \\
\hline LL value & \multicolumn{2}{|c|}{-7106.8929} & LL value & \multicolumn{2}{|c|}{-7094.8938} \\
\hline $\mathrm{p}$ - value & \multicolumn{2}{|c|}{0.0000} & $\mathrm{p}$ - value & \multicolumn{2}{|c|}{0.0000} \\
\hline
\end{tabular}

Note: $* \mathrm{p}<0.10 * * \mathrm{p}<0.05 * * * \mathrm{p}<0.01$

As can be seen clearly from Table 2 , the coefficients of the two models are very close to each other, In addition, both the $\mathrm{p}$ and LL values (maximum likelihood estimate) of the model are very satisfactory, the results show that the two models have higher reliability.

Specifically, the data in Table 2 conveys the following information:(1)The coefficient of Investment level (I) and Stock Returns (RETURN) in the previous year were significantly positive, indicating that the current level of investment in China's listed companies is affected by historical investment data and the company's overall external impression;(2) The coefficient of Debt Ratio $(L E V)$, Cash Stock $(C A S H)$ and Time to Market $(A G E)$ in the previous year were significantly negative indicating that the current level of investment in China's listed companies is not affected by the growth requirements within the company;(3)Most notable is the simultaneous change of the two coefficients in the two models, The first is the model I's Revenue Growth (GROWTH) to the model II 's Tobin's Q, Their coefficients from negative to positive, indicating that the use of Tobin's $\mathrm{Q}$ to measure the investment opportunities of the enterprise is more valuable,Second, is the 
coefficient of the Size of the company (SIZE), their coefficients from negative to positive at the same time, more powerful confirms the current judgment.

Identification of Inefficient Investment. The data in Table 2 also show, random, underinvestment and oveinvestment effect's constant coefficients are very significant, it shows that both model I and model II are ready for the identification of inefficient investment.

The identification of the non efficiency of investment is started from the variance decomposition of the estimation results from the two-tier stochastic frontier model. Taking into account the results shown in table 2, model II relative to the model I, the investment efficiency of the enterprise more explanatory, at the same time, taking into account the length of this paper, we only consider the model II total error variance decomposition. The results are shown in Table 3.

Table 3 The effect comparison of investment game

\begin{tabular}{cccc}
\hline & variable & sign & Value \\
\hline \multirow{2}{*}{ The offset effect } & Underinvestment & $\sigma_{\mathrm{u}}$ & 0.6279 \\
& Overinvestment & $\sigma_{w}$ & 0.5780 \\
Variance decomposition & Random error & $\sigma_{v}$ & 0.2525 \\
\hline \multirow{2}{*}{ Total variance of disturbance } & $\sigma_{\mathrm{u}}^{2}+\sigma_{\mathrm{v}}^{2}+\sigma_{\mathrm{w}}^{2}$ & 0.7920 \\
& Game proportion & $\left(\sigma_{\mathrm{u}}^{2}+\sigma_{\mathrm{v}}^{2}\right) /\left(\sigma_{\mathrm{u}}^{2}+\sigma_{\mathrm{v}}^{2}+\sigma_{\mathrm{w}}^{2}\right)$ & 0.9195 \\
& Curbed ratio & $\sigma_{\mathrm{u}}^{2} /\left(\sigma_{\mathrm{u}}^{2}+\sigma_{\mathrm{v}}^{2}+\sigma_{\mathrm{w}}^{2}\right)$ & 0.5413 \\
\hline
\end{tabular}

Table 3 gives the results of variance decomposition analysis and finds that the investment efficiency of enterprises is affected by two factors, such as ability to curb investment and ability to induce investors. Among them, the investment efficiency is affected by the former, which will lead to a negative impact on the investment efficiency of Listed Companies in China, $E(w-u)<0$.Total variance of disturbance is 0.7920 , among them, $91.95 \%$ can be explained by the investment game. By contrast, in the investment game, the power of curbed investment is greater than the power of induced investment. In short, the results show that the overall performance of Listed Companies in China is lack of investment, which is consistent with ZHANG Zongyi et al. (2012)[3].

Moreover, the two-tier stochastic frontier estimation also allows us to quantitatively analyze the degree of inefficiency of investment, specifically, we can calculate the conditional expectation of $u_{i t}$ and $w_{i t}$ to $\varepsilon_{i t}$, in order to the offset of the real investment to the optimal investment boundary is obtained for each enterprise in different years. The results are shown in Figure 1.

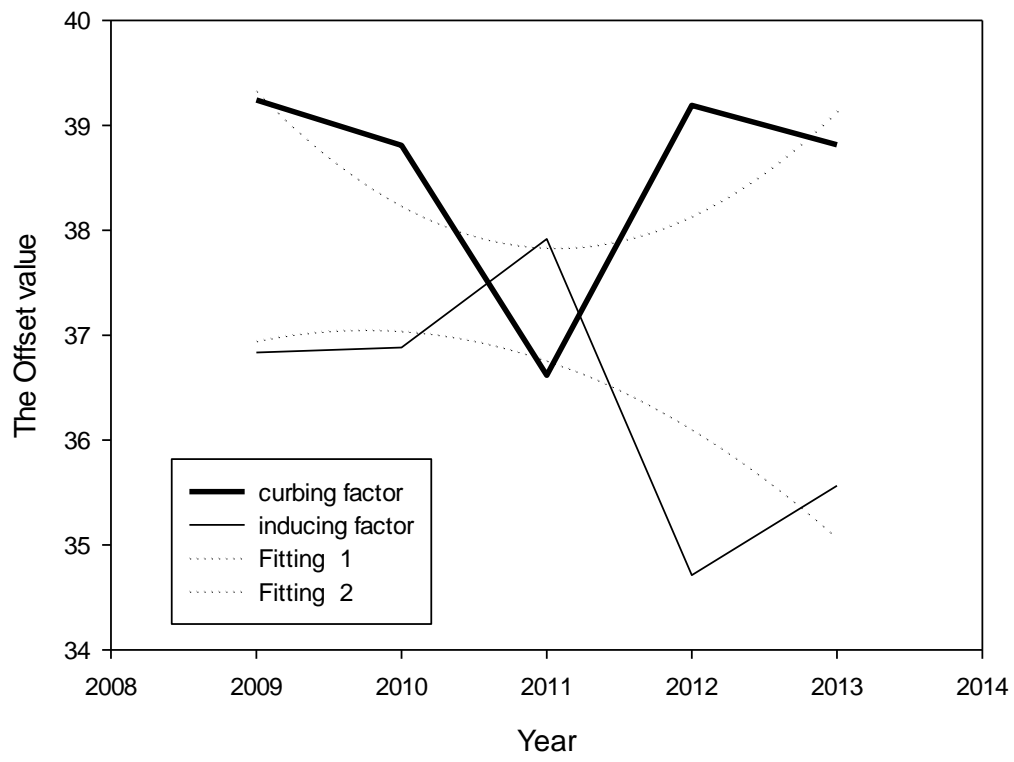

Fig. 1 Annual distribution of investment offset caused by the investment game 
As can be seen from Figure 1, the offset value of investment in different years is not balanced. Specifically: (1) On the whole, the effect of underinvestment is greater than that of overinvestment; (2) But from a local perspective, this is not always the case, the year of 2011 is a significant watershed, which can be clearly seen from table 4; (3) Compared with 2009, the net offset in the year 2013 was significantly enlarged.

Table 4 Annual distribution of net investment offset caused by the investment game

\begin{tabular}{|c|c|c|c|c|c|}
\hline Year & 2009 & 2010 & 2011 & 2012 & 2013 \\
\hline Net offset value & -2.41 & -1.93 & 1.30 & -4.48 & -3.25 \\
\hline
\end{tabular}

Early Warning of Investment Inefficiency. Two-tier stochastic frontier model can not only effectively identify the inefficient investment behavior of enterprises, what's more, it also hides a little-known feature of the rapid early warning of inefficient investment behavior.

In reviewing the previous literature, we found: (1) FANG Hongxing et al. (2013)[4] from the macro level, very creative to corporate governance, internal control into the same research framework, however, because of the internal heterogeneity of the two concepts, they can not find the real cause of the inefficient investment behavior; (2) HUANG Jun et al. (2012)[5] from the micro perspective, to explore the relationship between free cash flow and debt structure and inefficient investment behavior, but clearly found that free cash flow can lead to excessive investment and debt financing can inhibit the excessive investment of enterprises.

The above experience tells us that in order to quickly find the real driving force of inefficient investment, we need to give up the practice of naming the results of the two game forces directly into the effects of $\mathrm{A}$ and $\mathrm{B}$, back to the original assumption of the two-tier stochastic frontier: The first step is to identify the inefficient investment; The second step is to set up different models to explore the inevitable link between game factor and non efficiency behavior, to realize early warning the direction and size of non efficiency investment behavior.

Then, how to use the two-tier stochastic frontier model to realize the early warning of the inefficient investment behavior of the enterprise, which is our biggest interest. Existing studies tell us: On the one hand, Stulz (1990)[6] found that the manager has an incentive to invest in negative NPV, the purpose is to be able to control more resources, access to more on-the-job consumption, and ultimately to maximize their own interests; Hart (1995) [7] found that managers have a strong motivation to build a corporate empire; Richardson (2002) has also found that over investment enterprises in the United States also occur from time to time, in general, if the company has $\$ 1$ in residual cash flow, it will be spent in excess investment of 43 cents. On the other hand, Mconnell et al. (1995), Lang et al. (1996) [8], Ahn et al. (2006) [9] have verified the role of the debt governance, that is, debt financing can effectively restrain the abuse of free cash flow by the management.

Based on the above discussion, we make the following assumptions"(1) Free cash flow may lead to excessive investment, (2) Debt governance may lead to underinvestment" and Set up the following model:

$$
\begin{gathered}
\sigma_{u}=\exp \left(\alpha_{0}+\alpha_{1} \operatorname{Lev}+\alpha_{2}\right) \\
\sigma_{w}=\exp \left(\gamma_{0}+\gamma_{1} F c f+\gamma_{2}\right)
\end{gathered}
$$

Among them, Lev is the debt ratio, Fcf is cash flow. If the two models are included in the formula (4) for the new analysis, the results are shown in table 5: 
Table 5 Two-tier stochastic frontier estimation

\begin{tabular}{|c|c|c|c|c|c|}
\hline \multicolumn{3}{|c|}{ Model II } & \multicolumn{3}{|c|}{ Model III } \\
\hline Variable & coefficient & $\mathrm{p}$ - value & Variable & coefficient & $\mathrm{p}$ - value \\
\hline Investment: $\mathrm{I}_{\mathrm{it}}$ & & & Investment: $\mathrm{I}_{\mathrm{it}}$ & & \\
\hline Iit-1 & $0.793 * * *$ & 0.000 & lit-1 & $0.790 * * *$ & 0.009 \\
\hline Tobin $_{\mathrm{it}-1}$ & $0.050 * * *$ & 0.000 & TobinQ $_{\text {it-1 }}$ & $0.047 * * *$ & 0.009 \\
\hline $\operatorname{Lev}_{\mathrm{it}-1}$ & $-0.288 * * *$ & 0.000 & $\operatorname{Lev}_{\mathrm{it}-1}$ & $-0.285^{*}$ & 0.061 \\
\hline Cash $_{\text {it-1 }}$ & $-0.245 * * *$ & 0.000 & Cash $_{\text {it-1 }}$ & $-0.249 * *$ & 0.043 \\
\hline Age $_{i t-1}$ & $-0.004 *$ & 0.067 & Age $_{\text {it-1 }}$ & $-0.005 * * *$ & 0.002 \\
\hline Size $_{\text {it-1 }}$ & 0.005 & 0.560 & Size $_{\text {it-1 }}$ & $0.002 * * *$ & 0.009 \\
\hline Return $_{\text {it-1 }}$ & $0.093 * * *$ & 0.000 & Return $_{\text {it-1 }}$ & $0.097 * *$ & 0.014 \\
\hline Cons & $-0.690 * * *$ & 0.001 & Cons & -0.616 & 0.205 \\
\hline $\begin{array}{r}\text { Random: } \sigma_{\mathrm{v}} \\
\text { Cons }\end{array}$ & $-1.376 * * *$ & 0.000 & $\begin{array}{c}\text { Random: } \sigma_{\mathrm{v}} \\
\text { Cons }\end{array}$ & $-1.358 *$ & 0.090 \\
\hline Underinvestment: $\sigma_{\mathrm{u}}$ & \multicolumn{5}{|c|}{ Underinvestment: $\sigma_{\mathrm{u}}$} \\
\hline Cons & $-0.465 * * *$ & 0.000 & Cons & $-0.461 * *$ & 0.037 \\
\hline Overinvestment: $\sigma_{\mathrm{w}}$ & & \multicolumn{3}{|c|}{ Overinvestment: $\sigma_{\mathrm{w}}$} & 0.092 \\
\hline Cons & $-0.548 * * *$ & 0.000 & Cons & $-0.555^{* *}$ & 0.027 \\
\hline $\mathrm{N}$ & \multicolumn{2}{|c|}{5,665} & $\mathrm{~N}$ & \multicolumn{2}{|c|}{5,665} \\
\hline LL value & \multicolumn{2}{|c|}{-7094.8938} & LL value & \multicolumn{2}{|c|}{-7074.0256} \\
\hline $\mathrm{p}$ - value & \multicolumn{2}{|c|}{0.0000} & $\mathrm{p}$ - value & \multicolumn{2}{|c|}{0.0000} \\
\hline
\end{tabular}

Note: $* \mathrm{p}<0.10 * * \mathrm{p}<0.05 * * * \mathrm{p}<0.01$

Obviously, the two-tier stochastic frontier model (II) has the ability to easily identify inefficient investments,but the two-tier stochastic frontier model (III) , not only have this ability, but also possess the ability to warn against the possibility that game factors may lead to inefficient investments. The difference between the two models is that the exogenous variable of the latter is added to the scope of consideration in order to identify the forces of the game factor.

The empirical results show that the increase of free cash flow will increase the tendency of over investment, which is a true proposition, but it also shows that, for the present situation of China, the improvement of the corporate debt ratio is not a magic weapon to restrict the management's wanton investment. The empirical results further show that China's capital market is not perfect ,of course, it should be pointed out that the influence of debt governance is insignificant in comparison with the free cash flow. But we can imagine that if we extend the inspection time, the result will have dynamic changes, and this is exactly the purpose of this article.

\section{Conclusion}

Investment is the driving force of economic growth, but inefficient investment behavior can be seen everywhere. How to identify the inefficient investment, and grasp the early warning technology for inefficient investment behavior is very practical significance.

Based on the construction and upgrading of the two-tier stochastic frontier model to overcome the shortcomings of previous practices, we have carried on the thorough analysis to the Current topic, and has drawn the conclusion:

(1) The result of model comparison before and after upgrade is that:Compared to the annual growth rate, using of Tobin's Q to measure the investment opportunities of the enterprise is more valuable.

(2) The result of identifying inefficient investment behavior is that: From a macro perspective, the overall performance of Listed Companies in China is lack of investment; but on the micro level, the investment offset caused by investment game is not balanced in different years.

(3) The result of early-warning inefficient investment behavior is that:When exogenous variables are introduced into the upgraded model, the newly synthesized model is able to recognize the 
interference intensity of game factors; At the present stage of China, the improvement of the corporate debt ratio is not a magic weapon to restrict the management's wanton investment.

\section{Acknowledgments}

The work of this paper is supported by Hunan Provincial Department of Education funding research projects(Project NO: 15C1250).

\section{Reference}

[1] Hayashi, F. (1982). Tobin's marginal q and average q: a neoclassical interpretation. Econometrica, 50(1), 213-224.

[2] Lian, Yujun, \& Chung, ChingFan. (2008). Are chinese listed firms over-investing ${ }^{6}$. Social Science Electronic Publishing.

[3] Zhong, Y., \& Xian-Wei, L. U. (2012). Financing constraints,agent cost and information content of cash dividend policy. Soft Science.

[4] Fang, H., \& Jin, Y. (2013). Corporate governance, internal control and inefficient investment: theoretical analysis and empirical evidences.Accounting Research.

[5] Huang, J. A., \& Huang, N. (2012). Overinvestment, debt structure and governance effect: evidence from listed real estate companies in china.Accounting Research.

[6] Stulz, R. (1990). Managerial discretion and optimal financing policies.Journal of Financial Economics, 26(1), 3-27.

[7] Hart, O. (1995). Firms, contracts, and financial structure. Clarendon Press.

[8] Lang, L., Ofek, E., \& Stulz, R. (1996). Leverage, investment, and firm growth. Journal of Financial Economics, 40(1), 3-29.

[9] Ahn, S., Denis, D. J., \& Denis, D. K. (2006). Leverage and investment in diversified firms. Journal of financial Economics, 79(2), 317-337. 